\title{
Enhancement of DI Compression Ignition Engine Performance and Emission Using Diesel - Water Emulsion as Fuel
}

\section{Miqdam Tariq Chaichan}

Machines and Equipments Engineering Dept. / University of Technology/ Baghdad/ Iraq

\begin{abstract}
Emissions from diesel engines (rail, marine, construction equipment and other nonroad mobile sources) presently account for a significant part of the major pollutants (SOx, NOx, VOC, PM, CO, and noise) that are responsible for smog and for human health impacts.

The objective of this work is to identify effective ways to reduce emissions from direct injection Fiat diesel engine. The approach used here is the combustion of water-diesel emulsion in diesel engine, at different water ratios, at constant engine speed and variable engine load. The second set of tests was at constant load and variable engine speed. The results show improvement in $\mathrm{NOx}, \mathrm{UBHC}, \mathrm{CO}$ and $\mathrm{CO}_{2}$ reductions with increasing water emulsion percentage to $20 \%$, accompanied with brake specific fuel consumption (BSFC) reduction also.
\end{abstract}

Keywords: water-diesel emulsion, performance, emissions, PM, noise.

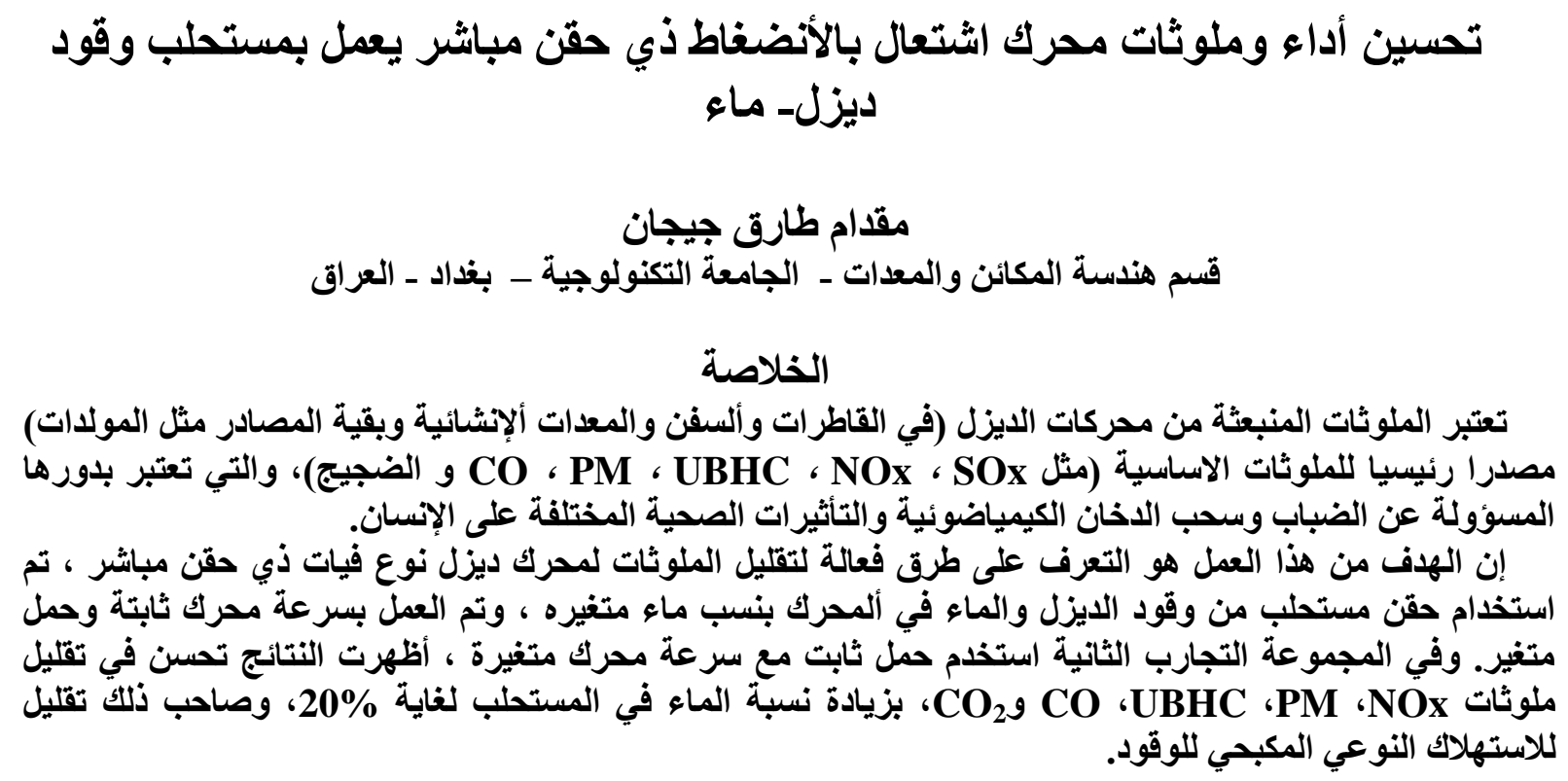




\section{Nomenclature}

$\begin{array}{ll}\text { TDC } & \text { top dead centre } \\ \text { BMEP } & \text { brake mean effective pressure } \\ \text { BSFC } & \text { brake specific fuel consumption } \\ \text { BTE } & \text { brake thermal efficiency } \\ \text { CA } & \text { crank angle } \\ \text { OIT } & \text { optimum injection timing } \\ \text { HC } & \text { unburned hydrocarbons } \\ \text { NOx } & \text { nitrogen oxides } \\ P M & \text { Particulate matters concentration in }\left(\mu \mathrm{g} / \mathrm{m}^{3}\right) \\ w_{1} & \text { Filter weight before sampling operation in }(\mathrm{g}) . \\ w_{2} & \text { Filter weight after sampling operation in }(\mathrm{g}) . \\ V t & \text { drawn air total volume }\left(\mathrm{m}^{3}\right) \\ Q_{t} & \text { Elementary and final air flow rate through the device }\left(\mathrm{m}^{3} / \mathrm{sec}\right) . \\ t & \text { Sampling time in (min). } \\ e_{R} & \text { Uncertainty in the results } \\ \mathrm{R} & \text { A given function of the independent variables } \mathrm{V}_{1}, \mathrm{~V}_{2}, \ldots, \mathrm{V}_{\mathrm{n}} \text { or } \mathrm{R}=\mathrm{R}\left(\mathrm{V}_{1}, \mathrm{~V}_{2},\right. \\ \text { ei } & \left.\ldots, \mathrm{V}_{\mathrm{n}}\right) .\end{array}$

\section{Introduction}

Diesel engines are widely used for mass transportation because of their high thermal efficiency and torque capacity. Higher fuel efficiency in the diesel engine is achieved by the high compression ratios along with relatively high oxygen concentration in the combustion chamber [1]. Diesel engines power most non-road equipments including construction, agricultural, marine vessels and locomotives. While the operational advantages of diesel engines are clear, the general public has considerable concerns regarding the pollution caused by diesel engines in the form of obnoxious odor, gas pollutants like NOx, HC, CO and particulate matter to atmosphere [2 \&3]. The main pollutants from diesel engines of most concern are NOx and particulate matter (PM). The mechanism of formation of NOx and particulate matter in the combustion chamber of diesel engines are contradictory and the simultaneous reduction of both is very difficult [4]. Generally, techniques that reduce NOx lead to an increase in smoke and particulate emissions and vice versa [5].

One promising method may be the use of water emulsified diesel which can economically accomplish the reduction of these two pollutants [6]. Water diesel emulsions can control both NOx and smoke emissions $[7 \&$ \&]. NOx emission decreases due to reduction in the gas temperature and increase in $\mathrm{OH}$ radical concentration [9]. Particulate emission decreases due to the micro-explosion phenomenon of water and increase in $\mathrm{OH}$ radical concentration $[10,11$ \&12]. There is also an improvement in the brake thermal efficiency at certain operating conditions [13 \& 14].

Emulsion is defined as a process where the initially mutually immiscible materials, such as water and oil, are mixed to form and maintain a temporary suspension by reducing their particulate sizes. The suspension goes back over time to the initial two-phase system where the materials separately exist as immiscible. The rate at which the emulsion returns to a twophase mixture depends on the types, viscosities, particulate size, and composition of mixed materials and the temperature [15 \& 16]. However, significant problems had kept the 
application of this technology away from commercial engines. The effect of the percentage of water added to diesel fuel is of high importance. Moreover, significant engine modifications may be necessary before using emulsions. One example is the adjustment of the injection timing to optimize engine performance when using emulsified fuel [17].

Many experimental studies were conducted in diesel engine using emulsified fuel $[18$ \& 19]. The fuel with a larger emulsion ratio results in a longer ignition delay and a longer premixed combustion phase [ $20 \& 21]$. The optimum water amount in the emulsified fuel is $20-25 \%$ for minimum NOx and BSFC [22 \& 23]. When the emulsified fuel is used improvement in specific fuel consumption and thermal efficiency were obtained due to the reduction in heat losses [24]. It was found that the best performance of the engine with respect to efficiency and NOx and soot emission was found when the engine is operating on emulsified fuel with $20 \%$ water by volume [25].

The aim of this work was to study the effect of performance and emission characteristics when water diesel emulsion is used as the fuel in a diesel engine. A multicylinder Fiat diesel engine was run on conventional Iraqi diesel fuel under variable load conditions at constant speed of $1500 \mathrm{rpm}$, and at constant load $44 \mathrm{kN} / \mathrm{m}^{2}$ and variable engine speed. Subsequently the engine was tested on emulsions of 10,20 and 30 percent by volume of water in diesel. Performance and emission parameters were obtained in all cases.

\section{Experimental Setup}

\section{Apparatus}

Experimental apparatus of engine under study is DI, water cooled four cylinders, in-line, natural aspirated Fiat diesel engine whose major specifications are shown in Table 1. The engine was coupled to a hydraulic dynamometer through which load was applied by increasing the torque. The Multigas mode 4880 emissions analyzer was used to measure the concentration of nitrogen oxide (NOx), unburned total hydrocarbon ( $\mathrm{HC}), \mathrm{CO}_{2}$ and $\mathrm{CO}$.

Overall sound pressure was measured by precision sound level meter supplied with microphone type 4615, as appears in fig. 1; the devise was calibrated by slandered calibrator type pisto phone 4220 .

Table (1): Tested engine specifications

\begin{tabular}{|l|l|}
\hline Engine type & 4cyl., 4-stroke \\
\hline Engine model & TD 313 Diesel engine rig \\
\hline Combustion type & DI, water cooled, natural aspirated \\
\hline Displacement & $3.666 \mathrm{~L}$ \\
\hline Valve per cylinder & two \\
\hline Bore & $100 \mathrm{~mm}$ \\
\hline Stroke & $110 \mathrm{~mm}$ \\
\hline Compression ratio & 17 \\
\hline Fuel injection pump & Unit pump \\
& 26 mm diameter plunger \\
\hline Fuel injection nozzle & Hole nozzle \\
& 10 nozzle holes \\
& Nozzle hole dia. $(0.48 \mathrm{~mm})$ \\
& Spray angle $=160^{\circ}$ \\
& Nozzle opening pressure $=40 \mathrm{Mpa}$ \\
\hline
\end{tabular}


Low volume air sampler type Sniffer L-30 (Fig. 2) was used to collect emitted PMs. Whatmann-glass micro-filters were used to collect PMs. These filters were weighted before and after the end of sampling operation which extend for one hour. Particulate matters (PMs) concentrations were determined by the equation:

$P M$ in $\left(\mu g / m^{3}\right)=\frac{w_{2}-w_{1}}{V t} \times 10^{6}$

$V t$ can be found by the equation:

$V t=Q_{t} \cdot t$

Each filter was kept in plastic bag temporarily, till the end of collecting samples operation finished, then filters were weighted and results were analyzed.

\section{Materials}

The commercial Iraqi diesel fuel and distilled water were used in this work. Iraqi diesel fuel characterized with its high sulfur content (it was $10000 \mathrm{ppm}$ in the present tested fuel). The water-diesel blended fuels were formed by blending together the following components, diesel fuel, water, surfactants or surface-active agents (for more information about these substances one can referred to [26]) and cetane number improver. The blending protocol was first to blend the cetane number improver and surfactant $(2 \% \mathrm{v} / \mathrm{v}$ for all water-diesel blended fuels) into the water, and then blend this mixture into the diesel fuel, then the water diesel emulsion was prepared. The stability time was about 5.25 months.

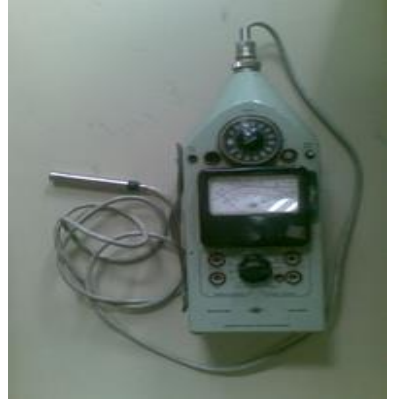

Figure (1): Overall sound pressure used in the tests

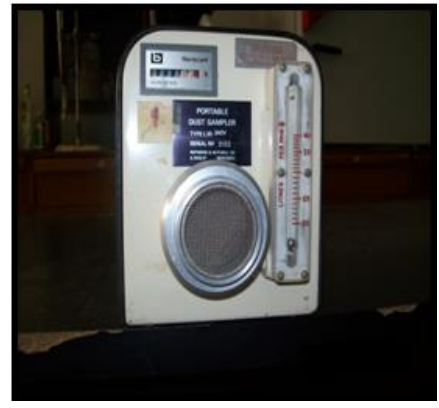

Figure (2), drawing air equipment to collect PM type Sniffer

The arrangement used for preparing the emulsion is shown in fig. 3. It consists of a pump, nozzle and a container. Known quantities of diesel, water, surfactant and cetane number improver were poured into the mixing jar and circulated in close loop using the pump. A good emulsion was obtained due to the shearing effects in the pump's impeller and in the jar where the high-speed stream, which ejected out of the nozzle, mixes with the rest of the contents. The emulsion was injected into engine using the

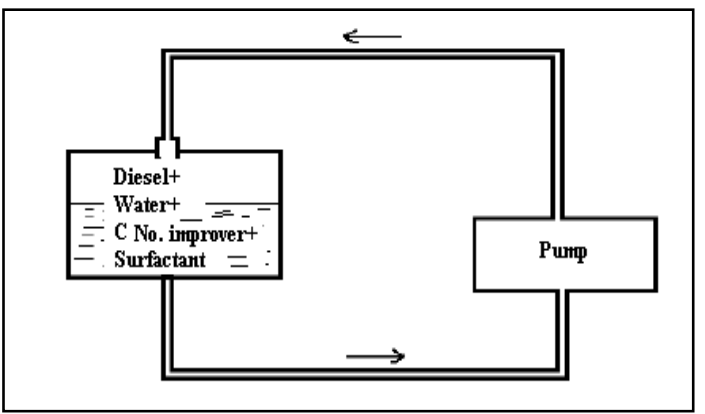

Figure (3): emulsion preparation standard injection system. Table 2 illustrates one of the used diesel and water diesel emulsion properties.

Three tested blends were prepared; the first one consisted of $10 \%$ water and $90 \%$ diesel fuel. It was named W10. The second blend was consisted of $20 \%$ water and $80 \%$ diesel fuel, 
and it was named W20. The last blend was named W30 consisted of 30\% water and 70\% diesel fuel. The cetane number improver and surfactant portion was with water.

Table (2): Properties of conventional diesel fuel and water diesel emulsion (W20)

\begin{tabular}{|c|c|c|c|}
\hline \multicolumn{2}{|c|}{ Property } & Diesel & W20 \\
\hline Density & $\left(\mathrm{kg} / \mathrm{m}^{3}\right)$ & 820 & 840 \\
\hline Cetane number & & 48.5 & 45.8 \\
\hline Lower heating value & $(\mathrm{MJ} / \mathrm{kg})$ & 42.31 & 40.76 \\
\hline Viscosity & $(\mathrm{cSt})$ & 2.87 & 3.15 \\
\hline Final boiling point & $\left({ }^{\circ} \mathrm{C}\right)$ & 369.8 & 343.2 \\
\hline \multicolumn{4}{|l|}{ Element analysis } \\
\hline $\mathrm{C} \%$ & $(\mathrm{w} / \mathrm{w})$ & 86 & 75 \\
\hline $\mathrm{H} \%$ & $(\mathrm{w} / \mathrm{w})$ & 12.935 & 17.3 \\
\hline $\mathrm{S} \%$ & $(w / w)$ & 1 & 0.642 \\
\hline $\mathrm{N} \%$ & $(w / w)$ & 0.065 & 0.058 \\
\hline $\mathrm{O} \%$ & $(\mathrm{w} / \mathrm{w})$ & - & 7 \\
\hline Molecular weight & (g/mole) & 211 & 191 \\
\hline
\end{tabular}

The presence of water generates different physicochemical modifications of the fossil fuel, notably reductions of the cetane number, lower heat content, viscosity, flash point, and pour point. These modifications changed the spray evaporation properties, combustion performance, and engine-out emissions.

The following equations were used in calculating engine performance parameters [27]:

1- Brake power

$b p=\frac{2 \pi * N * T}{60 * 1000} \quad k W$

2- Brake mean effective pressure

bmep $=b p \times \frac{2 * 60}{V_{s n} * N} \mathrm{kN} / \mathrm{m}^{2}$

3- Fuel mass flow rate

$\dot{m}_{f}=\frac{v_{f} \times 10^{-6}}{1000} \times \frac{\rho_{f}}{\text { time }} \mathrm{kg} / \mathrm{sec}$

4- Air mass flow rate

$\dot{m}_{a, a c t .}=\frac{12 \sqrt{h_{o} * 0.85}}{3600} \times \rho_{\text {air }} \frac{\mathrm{kg}}{\mathrm{sec}}$

$\dot{m}_{a_{\text {theo. }}}=V_{\text {s.n }} \times \frac{N}{60 * 2} \times \rho_{\text {air }} \frac{\mathrm{kg}}{\mathrm{sec}}$

5- Brake specific fuel consumption

$b s f c=\frac{\dot{m}_{f}}{b p} \times 3600 \frac{\mathrm{kg}}{\mathrm{kW} \cdot \mathrm{hr}}$

6- Total fuel heat

$Q_{t}=\dot{m}_{f} \times L C V \quad k W$

7- Brake thermal efficiency

$\eta_{b t h .}=\frac{b p}{Q_{t}} \times 100 \quad \%$ 
The tests were conducted to specify load effects on engine performance and emissions; they were achieved at constant engine speed $1500 \mathrm{rpm}$, and constant injection timing $38^{\circ} \mathrm{BTDC}$. While the tests performed to specify engine speed effects were conducted at constant load $\left(44 \mathrm{kN} / \mathrm{m}^{2}\right)$ and $38^{\circ} \mathrm{BTDC}$ injection timing.

\section{Experimental errors and uncertainties}

For every measuring device there is a difference between measured and true values of quantity is known as an error. By determining the value of that error, an uncertainty is defined. The uncertainties in each individual measurement lead to uncertainties in experiment [28]. In general, the uncertainty in the results is:

$e_{R}=\left[\left(\frac{\partial R}{\partial V_{1}} e_{1}\right)^{2}+\left(\frac{\partial R}{\partial V_{2}} e_{2}\right)^{2}+\cdots+\left(\frac{\partial R}{\partial V_{n}} e_{n}\right)^{2}\right]^{0.5}$

The partial derivative $\frac{\partial R}{\partial V_{1}}$ is a measure of the sensitvity of the result to a single variable.

The summarized analysis of the experimental accuracy of the measuring properties for some selected measuring devices is shown in table (3). From these values the experiments uncertainties can be calculated:

$$
\begin{gathered}
e_{R}=\left[(0.045)^{2}+(0.07)^{2}+(0.95)^{2}+(0.98)^{2}+(1.24)^{2}+(0.7)^{2}+(0.022)^{2}\right. \\
\left.+(1.09)^{2}\right]^{0.5}=\mp 2.255
\end{gathered}
$$

This result confirms an uncertainty of less than $5 \%$ in measurement of present study was achieved. For each condition, three tests were conducted to minimize random errors in the experiments. From the results of these experiments for each condition, the average value is reported along with more than $95 \%$ confidence intervals.

Table (3): Experimental Accuracies

\begin{tabular}{|l|c|}
\hline \multicolumn{1}{|c|}{ Measurements } & Accuracies in present study \\
\hline Thermocouples & 0.045 \\
\hline Air flow meter & 0.07 \\
\hline Fuel flow meter & 0.95 \\
\hline Engine speed & 0.98 \\
\hline Engine torque & 1.24 \\
\hline Sound pressure level & 0.7 \\
\hline Emitted exhaust gases concentrations & 0.022 \\
\hline PM concentrations & 1.09 \\
\hline
\end{tabular}

\section{RESULTS and DISCUSSION}

\section{Load effects:}

Brake specific fuel consumption (bsfc) is the rate of fuel consumption divides by the rate of power production. Brake specific fuel consumption of test fuels are shown in fig. 4. BSFC descend from lower to medium loads level then it rise again from medium to high loads. BSFC reduced for $10 \%$ water (W10) and $20 \%$ water (W20), and it increased for $30 \%$ water (W30). The reduction was about $2.4 \%$ for $\mathrm{W} 10$ and $5.6 \%$ for $\mathrm{W} 20$, and the increment was about $6.3 \%$ for $\mathrm{W} 30$. 
As Ghojel [4] mentioned the rate of heat release found to increase with percentage of water. The reason seems to be the fact that the mixture is better prepared due to prolonged ignition delay. Experimental investigations showed that strong micro-explosions of a group of droplets can occur in the specific regions of the luminous flame near the spray tip. Microexplosions of the emulsion fuel seem to enhance the mixing of fuel with surrounding air for faster and more efficient combustion also resulting in a higher heat release rate. The cylinder pressure is increasing with the percentage of water in the emulsion, producing better engine output, reducing BSFC for these emulsion rates. For W30 the cooling effect of water vaporization which cool down the mixture temperatures, increasing the delay period, which resulted in reducing output and as a result increasing BSFC.

W10 and W20 engines gave better brake thermal efficiencies for all tested loads, while W30 blends engine record a decline in resulted brake thermal efficiencies for low and medium loads, and a limited improvement at high loads only, because of better combustion with more heat released, as fig. 5 represents. Abu-Zaid [6] reported that the average increase in brake thermal efficiency for $20 \%$ water emulsion is approximately $3.5 \%$ over the use of diesel for the engine speed range studied, while here in this work, for constant speed 1500 $\mathrm{rpm}$, and for the whole engine tested loads range the increment in brake thermal efficiency was $4.5 \%$ with W20.

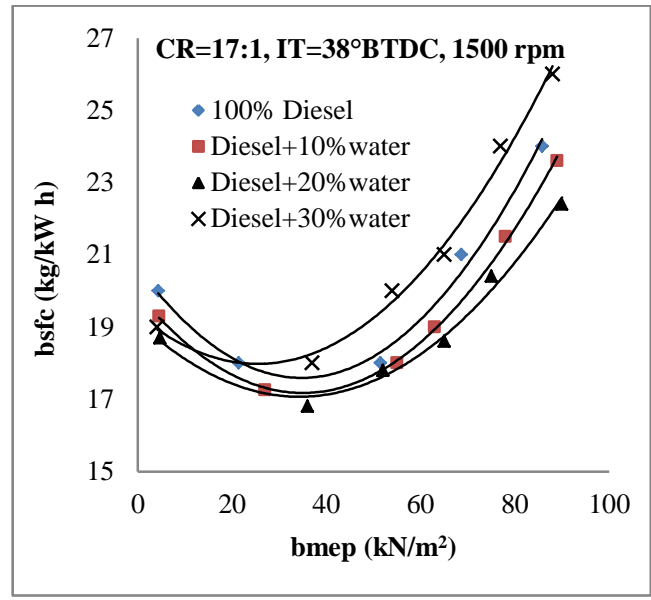

Figure (4): Water addition effect on bsfc for variable range of loads

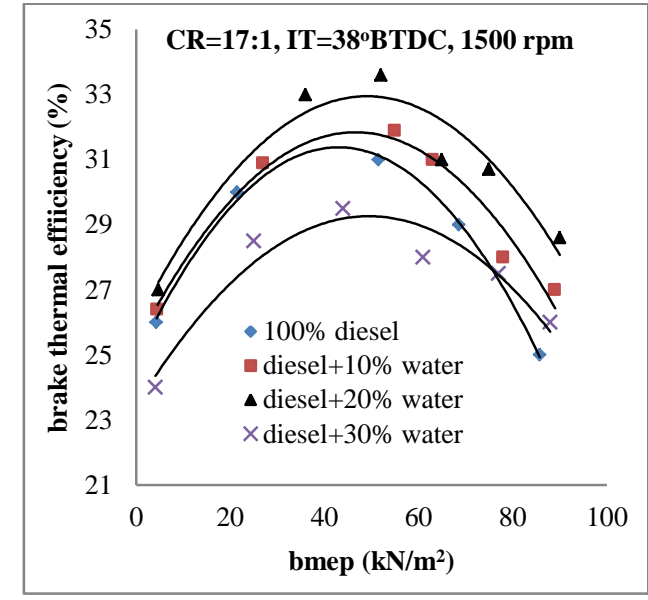

Figure (5): Water addition effect on brake thermal efficiency for variable range of loads

Brake thermal efficiency deteriorates for W30 because of mixture temperature reduction due to the effect of cooling concomitant with water evaporation, which reduced combustion chamber temperature and pressure, hence elongated delay period, and this reduced the output power, in addition to incomplete combustion.

Fig. 6 represents the resulted exhaust gas temperatures with water emulsion, these temperatures reduced for $\mathrm{W} 10$ and $\mathrm{W} 20$, and increased for W30. The reductions for W10 was $8.8 \%$, and for $\mathrm{W} 20$ was $19.6 \%$, while the increment for $\mathrm{W} 30$ was $13.81 \%$. Adding water to form blends W10 and W20 improved brake thermal efficiency and BSFC and exhaust gas temperatures for the diesel engine, in the other hand increasing water emulsion to $30 \%$ lost these improvements, which gives an indication about the optimum water emulsion percentage lies between W10 and W20.

The variation of NOx formation with load is shown in fig. 7 at constant engine speed and compression ratio for diesel combustion. NOx concentrations are increased with load as the mass of fuel injected is increased giving higher flame temperature. 
Fig. 7 shows the NOx concentration rates with percentage of water in the emulsion. The vaporization and sensible water heats reduces the local adiabatic temperature and thus NOx formation. From the experimental results, it is found that $9.8,21.5$ and $29.89 \%$ of reduction in NOx is achieved with 10, 20 and $30 \%$ dilution of diesel with water respectively.

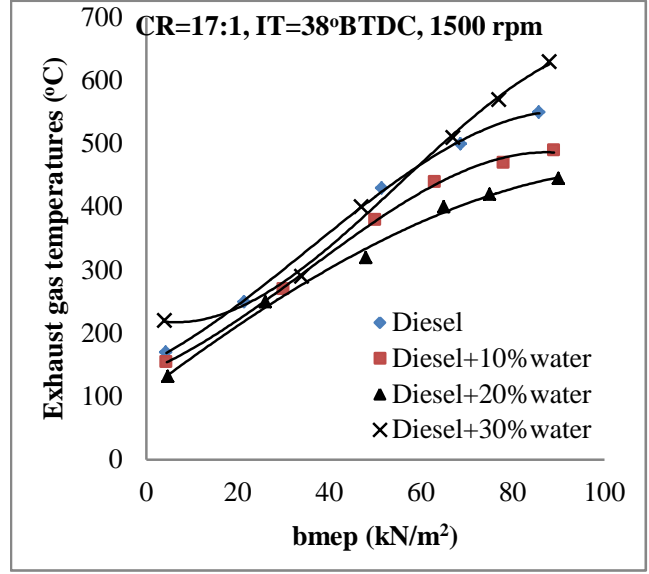

Figure (6): Water addition effect on exhaust gas temperatures for variable

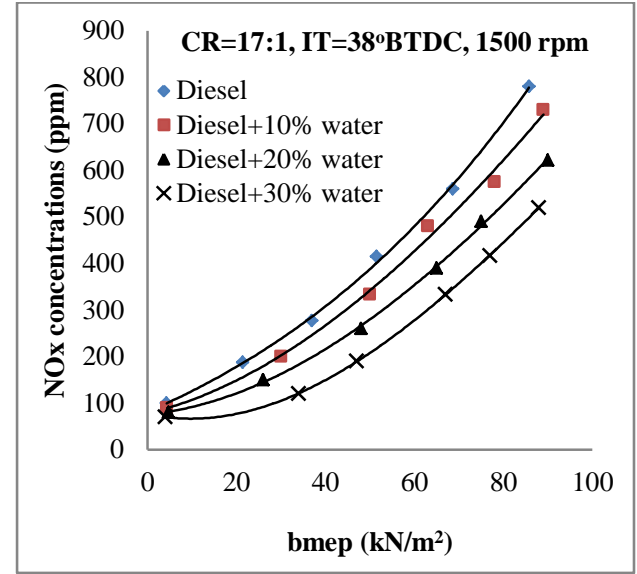

Figure (7): Water addition effect on NOx concentrations for variable range of

Adding water emulsion reduces PM concentrations remarkably as fig. 8 demonstrates. Two factors contribute to this trend: First, the reduction in sulfer content (which assists in a higher probability of agglomeration of particulate matters) due to water addition. Secondly, the lower exhaust temperatures decelerate PM formation process. The reductions in PM concentrations for the whole tested load range were $4.29,12.18$ and $22.8 \%$ for W10, W20 and W30 respectively compared with neat diesel. The figure clarifies that PM concentrations are insignificantly reduced at low loads, while at high loads the reductions are high. The present results agree with reference [29] results.

Water addition effect on unburned hydrocarbons (UBHC) illustrated in fig. 9. UBHC reduced for W10 and W20 by 7.8 and $20 \%$ respectively, and increased by 15.6 for W30. Combustion improvements reduced the resulted UBHC, while its deterioration increased these concentrations.

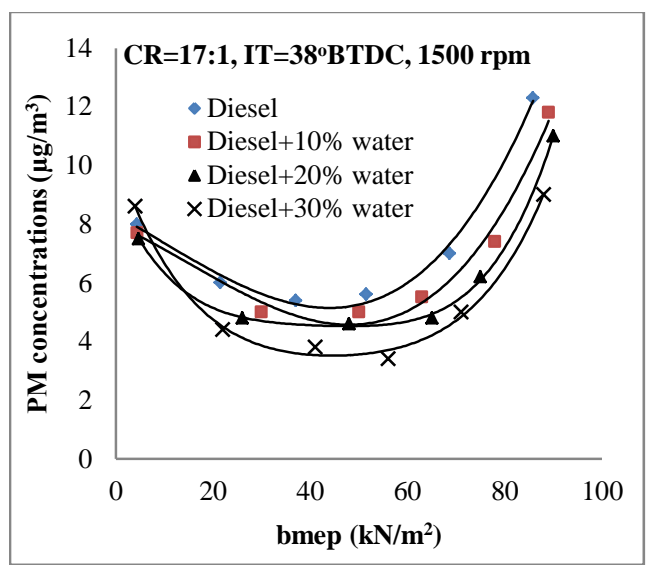

Figure (8): Water addition effect on PM concentrations for variable range of loads

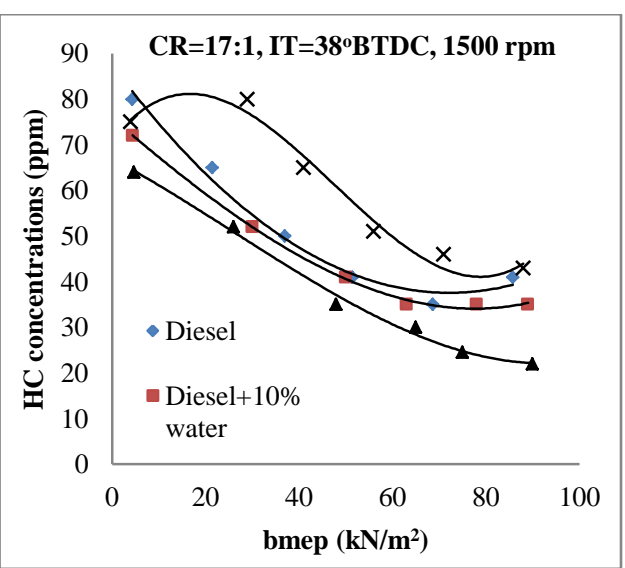

Figure (9): Water addition effect on HC concentrations for variable range of loads 
Diesel engine is known to produce much more noise than that produced by a spark ignition Combustion improvements with water additions reduced $\mathrm{CO}$ concentrations for $\mathrm{W} 10$ and W20, by 9 and 27\% respectively. Adding more water complicated the burning phenomena, and reduced the combustion quality, increasing $\mathrm{CO}$ concentrations by about $23 \%$, as fig. 10 represents.

As mentioned in the last figures, combustion improvements with water additions increased $\mathrm{CO}_{2}$ concentrations for $\mathrm{W} 10$ and $\mathrm{W} 20$, by 5.88 and $9.3 \%$ respectively. This is reasonable because reducing UBHC and $\mathrm{CO}$ cause increasing of $\mathrm{CO}_{2}$ concentrations. Adding more water complicated the burning phenomena, reducing $\mathrm{CO}_{2}$ concentrations by about $23.4 \%$, as fig. 11 represents, because the increment in $\mathrm{UBHC}$ and $\mathrm{CO}$ concentrations brought forward from $\mathrm{CO}_{2}$ quotient.

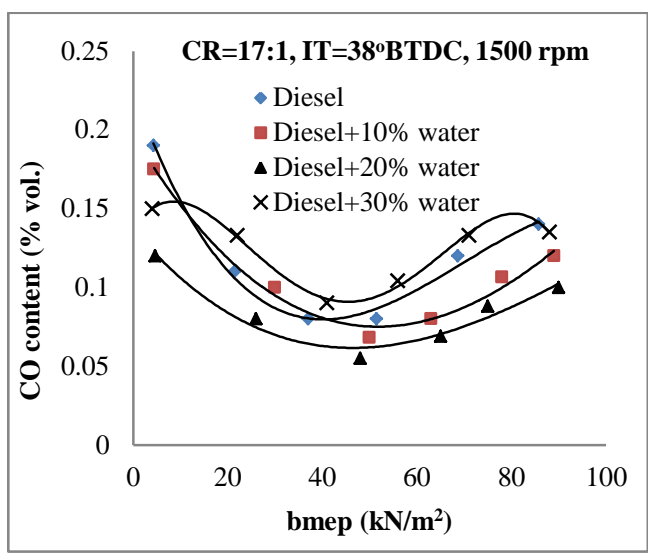

Figure (10): Water addition effect on CO concentrations for variable range of loads

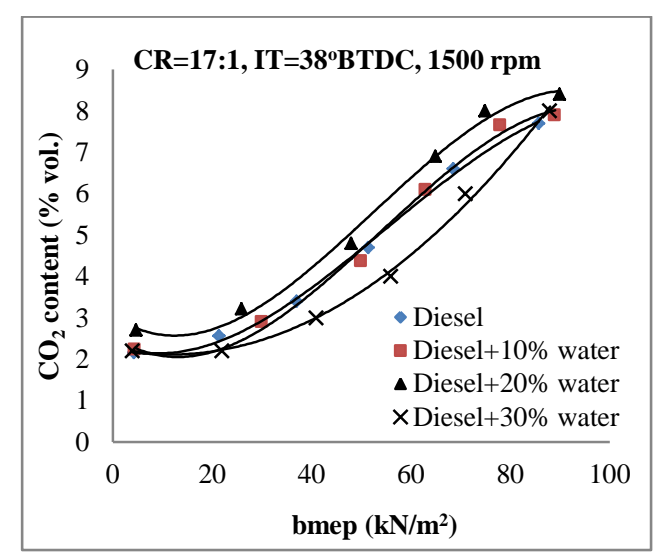

Figure (11): Water addition effect on $\mathrm{CO}_{2}$ concentrations for variable range of loads

engine. Noise is transmitted throughout the engine block as vibration, which can cause audible noise to the human ear at a different spectrum of frequencies. In the previous tests engine noise was measured, as fig. 12 shows. Adding water emulsions W10 and W20 reduced noise by 8.466 and $13.9 \%$ respectively, while W30 increased noise by $2.08 \%$ indicating rough and hard combustion.

\section{Engine speed effect}

Brake power (bp) increased for medium speeds and reduced for both low and high speeds, as fig. 13 shows, also it increased for W10 and W20 by 2.8 and $4 \%$ respectively, but it reduced for W30 by $4.5 \%$. Moving from low towards medium speeds improves mixture preparations and increases temperatures inside combustion chambers, as a result the burning performance improved, putting in mind that W10 and W20 increases the pressure and temperature inside the chamber. Increasing engine speed from medium to high speeds, increases turbulence inside the chamber, and reduces the preparation time and diesel-water emulsion delay period, resulting in declined bp, especially with W30 which gives hard and difficult combustion as seen in previous figures.

Increasing engine speeds needs more fuel which means higher BSFC, as fig. 14 represents, but adding water emulsions W10 and W20 reduced BSFC by 1.22 and $6.33 \%$ respectively, indicating better burning inside the chamber. In the meanwhile, increasing added water to W30 increased BSFC by $4.29 \%$.

Exhaust gas temperatures reduced with increasing water emulsion percentage for W10 and W20 and increased for W30, for the same reasons mentioned before, that's what is indicated in fig. 15. 


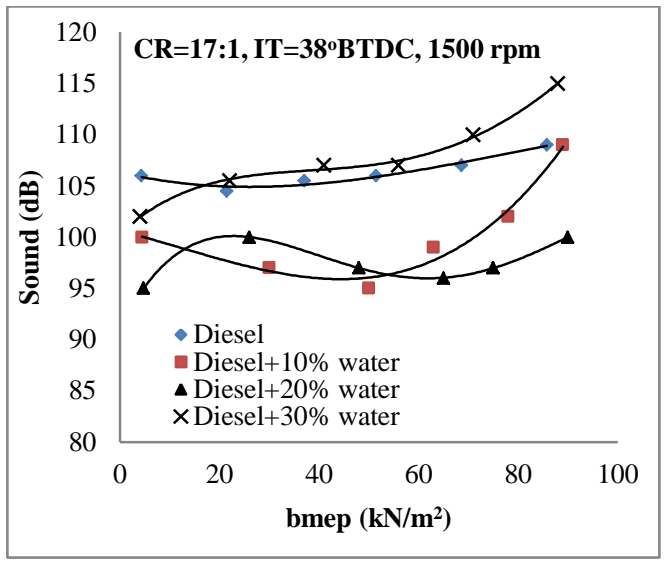

Figure (12): Water addition effect on engine noise for variable range of loads

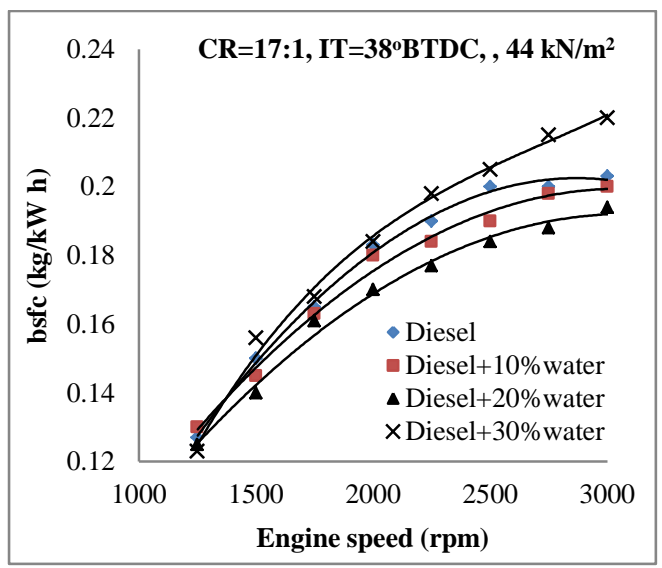

Figure (14): Water addition effect on bsfc for variable range of engine speeds

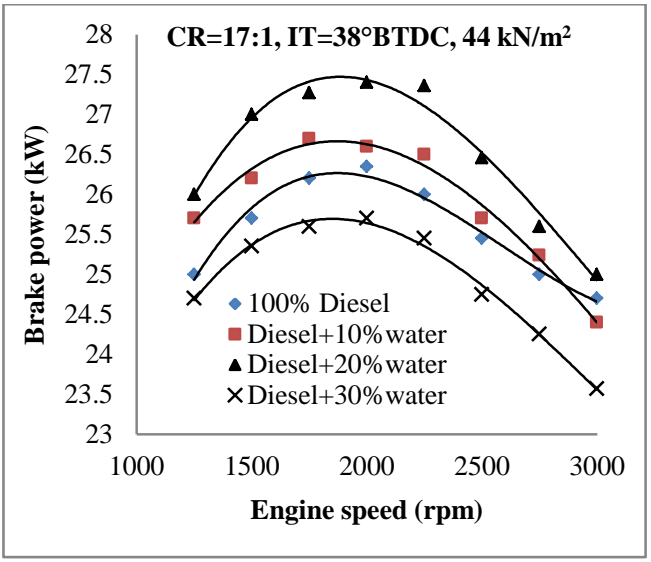

Figure (13): Water addition effect on engine brake power for variable range of engine speeds

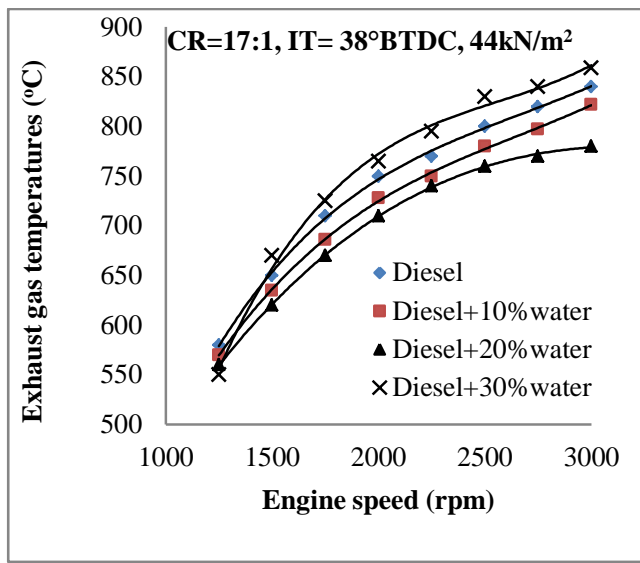

Figure (15): Water addition effect on exhaust gas temperatures for variable range of engine speeds

NOx concentrations reduced for all emulsions percentages, as fig. 16 shows, these concentrations reduced by $12,15.37$ and $26.3 \%$ for W10, W20 and W30 respectively. Many researchers concluded that every $1 \%$ water emulsion addition reduced NOx concentrations by $1 \%$; this work approved these true conclusions.

Fig. 17 shows how the volumetric rate of water in a water-diesel emulsion affects the PM concentrations. There are very large decrements in emitted PM by adding water. The reductions were $19.1,28.67$ and $47.6 \%$ for $\mathrm{W} 10$, W20 and W30 respectively compared to diesel. Increased water percentage gives a combination of an increase in mixing of air and fuel as a result of the micro explosion phenomenon. Also, a decrement in flame temperature is caused by the water addition. The introduction of water alters the quantities of fuel and air during the pre-mix period and acts as a source of oxygen, thus making it a less fuel rich environment and allowing for soot to be oxidized as reference [30] explained. 


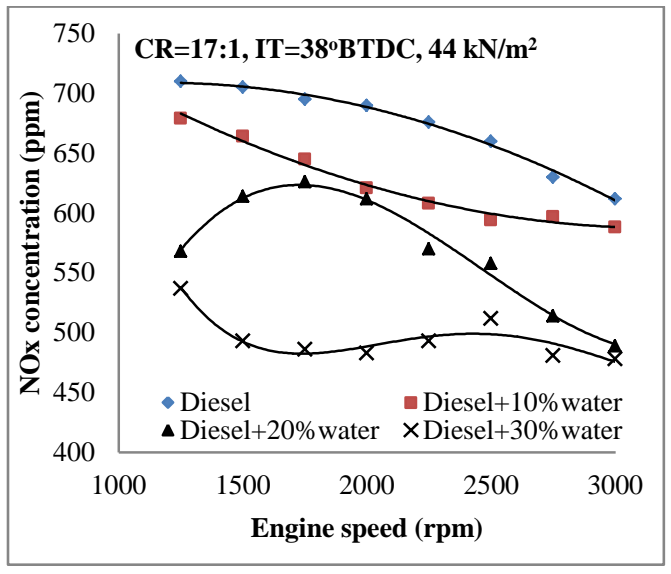

Figure (16): Water addition effect on NOx concentrations for variable range of engine speeds

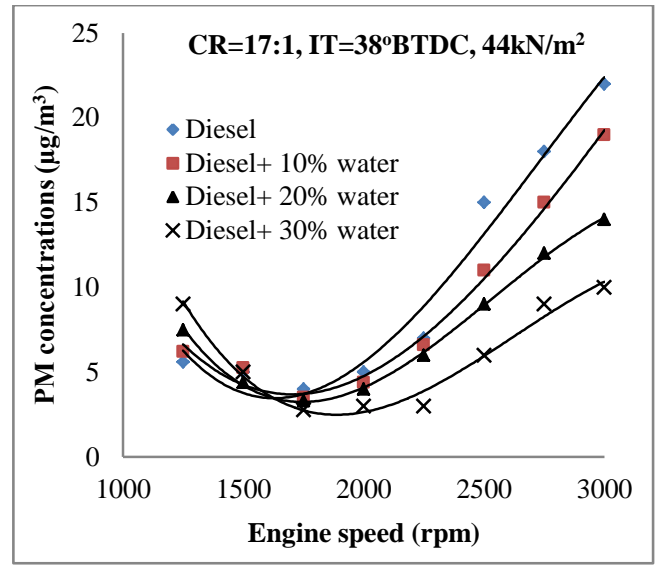

Figure (17): Water addition effect on PM concentrations for variable range of engine speeds

$\mathrm{CO}$ concentrations reduced for medium speeds and increased for low and high speeds, it also reduced for 10 and W20 and increased for W30, as fig. 18 represents. CO concentrations represent uncompleted combustion and increase at very lean and rich mixtures, but in diesel engine where the mixture always lean, the appearance of $\mathrm{CO}$ referred to local non homogeneity inside combustion chamber, fed by low turbulence at low speed, or by high turbulence at high speeds.

Water emulsion can be used to control part of engine emissions, as it reduces NOx, $\mathrm{CO}$ and UBHC concentrations. Fig. 19 represents the effect of water emulsions on UBHC concentrations, these concentrations reduced for W10 and W20, but it increased for W30. Adding water emulsions with 10 or $20 \%$ insure what was mentioned above, but adding water in $30 \%$ or more percentages will obstruct the combustion and increase the pollutions.

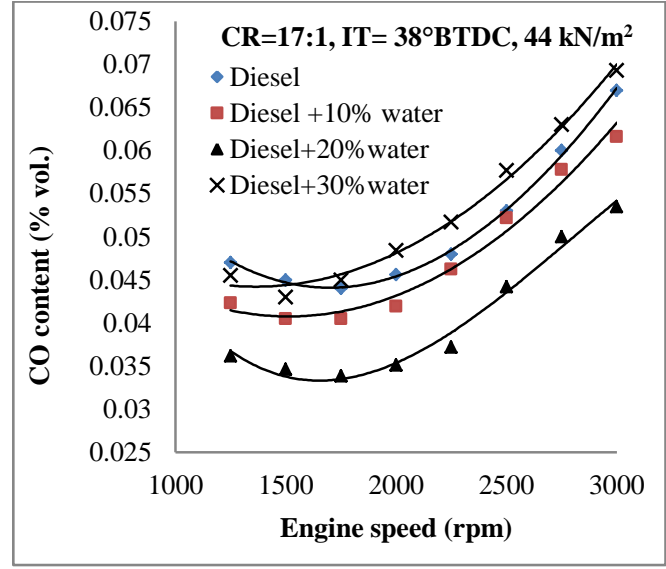

Figure (18): Water addition effect on engine brake power for variable range of engine speeds

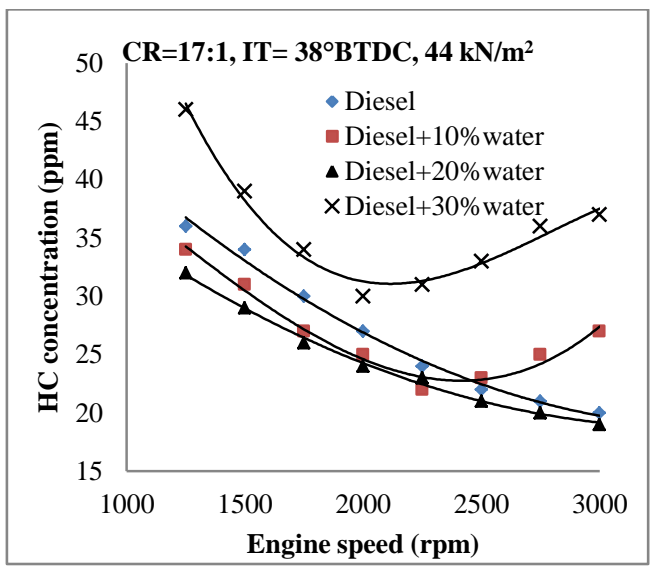

Figure (19): Water addition effect on engine brake power for variable range of engine speeds

\section{Conclusions}

Fuel modification can be considered a promise way for reducing diesel engines emissions up to high percentages. Although this paper has discussed one way which is water addition in 
specific percentages, this method proved practically the possibility of improving engine performance and reducing its emissions, and the followings are some of the concluded points:

1. Brake specific fuel consumption showed a little improvement with W10 and W20, but it retreated with W30.

2. Water addition with $\mathrm{W} 10$ and $\mathrm{W} 20$ reduced engine emissions $\left(\mathrm{CO}, \mathrm{CO}_{2}, \mathrm{UBHC}\right)$ for all engine load range.

3. Water addition with W10 and W20 reduced NOx and PM in the same time.

4. Water addition with $\mathrm{W} 10$ and W20 reduced engine noise for all engine load range.

5. Fuel-water emulsion injection into the cylinder reduced engine emissions $\left(\mathrm{CO}, \mathrm{CO}_{2}\right.$, UBHC, NOx and PM) for engine speed range (1250 to $3000 \mathrm{rpm}$ ).

The main aim of the work was to test this method as assistant in reducing NOx and PM concentrations together, but the results verified that fuel-water emulsion injection into the cylinder reduces $\mathrm{CO}, \mathrm{CO}_{2}$ and $\mathrm{UBHC}$ also. Due to its simplicity in system installation and operation, it has found favor to be used directly with no minor engine changes.

\section{References}

[1] Kannan1 K \& Udayakumar M, NOx and HC emission control using water emulsified diesel in single cylinder engine, Asian Research Publishing Network (ARPN), vol. 4, No. 8, 2009.

[2] Nadeem M, Rangkuti C, Anuar K, Haq M R U, Tan I B \& Shah S S, Diesel engine performance and emission evaluation using emulsified fuels stabilized by conventional and gemini surfactants, Fuel, vol. 85, pp: 2111-2119, 2006.

[3] El-Sinawi A H, Water- surrogate fuel emulsion combustion effect on $\mathrm{CO}$ and $\mathrm{NOx}$ emissions, Int. J. of Thermal \& Environmental Engineering, vol. 1, No. 2, pp: 99-108, 2010.

[4] Ghojel J, Honnery D \& Al-Khaleefi K, Performance, emission and heat release characteristics of direct injection diesel engine operating on diesel oil emulsion. Applied Thermal Engineering, vol. 26, pp: 2132-2141, 2006.

[5] Armas O, Ballesteros R, Martos F J \& Agudelo J R, Characterization of light duty diesel engine pollutant emissions using water-emulsified fuel, Fuel, vol. 84, pp: 1011-1018, 2005.

[6] Abu-Zaid M, Performance of single cylinder, direct injection diesel engine using water fuel emulsions, Energy Conversion and Management, vol. 45, pp: 697-705, 2004 a.

[7] Tran X T \& Ghojel J I, Impact of introducing water into the combustion chamber of diesel engines on emissions-an overview, Proceedings of the 5th Aisa-Pasific Conference of Combustion, July 17-20, University of Adelaide, Adelaide, Australia, pp: 233-236, 2005.

[8] De Fries T H, Anthony J W, Kishan S, Ullman T L, Matthews R D \& Lewis D J, The Texas diesel fuels project, Part 1: Development of txdot-specific test cycles with emphasis on a "route" technique for comparing fuel/water emulsions and conventional diesel fuels, SAE Paper No. 2004-01-0090, 2004.

[9] Jankowski A, Influence of chosen parameters of water fuel micro emulsion on combustion processes, emission level of NOx and fuel consumption of CI engine, Journal of KONES Power train and Transport, vol. 18, No. 4, 2011.

[10] Dec J E, Canaan R E \& Tree D R, The effect of water-emulsified fuel on diesel soot formation, 219th National Meeting, American Chemical Society, March 2000.

[11] Duncan D A, Langer D A \& Marshall J C, Emulsion fuels- improving the environment today, SAE Conference, Vienna, Austria, April, 2001.

[12] Jankowski, A, Sowa K \& Zablocki M, Some aspects using of micro emulsion fuel-water for supply of combustion engines, Journal of KONES, Power train and Transport, vol. 16, No. 4, pp: 531-538, 2009. 
[13] Park J W, Huh K Y, Park K H, Experimental study on the combustion characteristics of emulsified diesel in a rapid compression and expansion machine. Proc. Instn. Mech. Engrs, vol. 214, pp: 579-585, 2000.

[14] Ashok M P \& Saravanan C G, Combustion characteristics of compression engine driven by emulsified fuel under various fuel injection angles, J. Energy Resource Technology, vol. 129, No. 4, pp: 325-332, 2007a.

[15] Schulz P, Dalix L, Letoffe J M \& Faure Y, INSEDELF: method of studying separation in liquid-liquid phase application to water-diesel fuel emulsions. Fuel; vol. 83, pp: 137-42, 2004.

[16] Ashok M P \& Saravanan C G, Performance and emission of the emulsified fuel in a DI diesel engine using oxygenated additive diethyl ether with surfactant of Span-80, Energy Fuels, vol. 21, No. 4, pp: 1878-1882, 2007 b.

[17] Cherng-Yuan L \& Li-Wei C, Engine performance and emission characteristics of threephase diesel emulsions prepared by an ultrasonic emulsification method, Fuel, vol. 85, pp: 593-600, 2006.

[18] Dluska E, Hubacz R \& Wronski S, Simple and Multiple Water Fuel Emulsions Preparation in Helical Flow, Turkish J. Eng. Env. Sci., vol. 30, pp: 175-182, 2006.

[19] Piaseczny L \& Zadrag R, Researches of influence of water delivery to cylinder on parameters of combustion process and toxicity of CI engine, Proceeding of Polish CongressPTNSS, Bielsko Biala/Szczyrk, September, Poland, 2005.

[20] Piaseczny L \& Zadrag R, Water fuel emulsions properties for naval diesel engines, Proceeding of Polish Conference on Gas Engines, Czestochowa, June, Poland, 2006.

[21] El-Sinawi A H, Impact of combustion of water in fuel on polycyclic aromatic hydrocarbon (Pah's) precursors Formation, World Academy of Science, Engineering and Technology, vol. 80, 2011.

[22] Abu-zaid M, An experimental study of the evaporation characteristics of emulsified liquid droplets, Heat Mass Transfer, vol. 40, No. 9, pp: 737-741, 2004 b.

[23] Selim M Y E \& Ghannam M T, Combustion study of stabilized water-in-diesel fuel emulsion, Energy Sources, Part A: Recovery, Utilization, and Environmental Effects, vol. 32, No. 3, pp: 256-274, 2009.

[24] Alahmer A, Yamin J, Sakhrieh A \& Hamdan M, Engine performance using emulsified diesel fuel. Energy Con. Manage., vol. 51, No. 8, pp: 1708-1713, 2009.

[25] Fayyad S M, Abu-Ein S, Al-Marahleh G, Al-Momani W, Al-Momani M, Abulghanam Z, Badran $\mathrm{O} \&$ Abu-Rahmah T, Experimental emulsified diesel and benzen investigation, Research Journal of Applied Sciences, Engineering and Technology, vol. 2, No. 3, pp: 268273, 2010.

[26] Rosen M J, Surfactants and interfacial phenomenon, New York: Wiley; 2004.

[27] Keating E L, Applied combustion, $2^{\text {nd }}$ edition, Taylor \& Francis Group, LLC, 2007.

[28] ASHREA GIUDE LINE. Guide engineering analysis of experimental data, Guideline 21986.

[29] Lif A, Holmberg K, Water-in-diesel emulsions and related systems, Advances in Colloid and Interface Science, vol. 123, No. 126, pp: 231-239, 2006.

[30] Yatsufusa T, Kumura T, Nakagawa Y and Kidoguchi Y, Advantage of using water emulsified fuel on combustion and emission characteristics. Proceedings of the European Combustion Meeting, pp: 1-6. 2009. 